\title{
Thinking Like an Engineer: Using Engineering Habits of Mind and Signature Pedagogies to Redesign Engineering Education
}

\author{
http://dx.doi.org/10.3991/ijep.v6i2.5366 \\ B. Lucas and J. Hanson \\ University of Winchester, Winchester, United Kingdom
}

\begin{abstract}
In order to attract more young people into engineering and ensure that they are well equipped to meet future professional challenges we need to know how successful engineers think and act when faced with challenging problems. Using a mixed methods approach this study investigated the habits of mind that engineers use most frequently when engaged in the core activity of "making" things or "making things work better". We identified the six most distinctive learning dispositions, or engineering "habits of mind" [EHoM] that engineers frequently deploy. Our research then explored ways in which the teaching of engineering might be re-designed to cultivate EHoM using "signature pedagogies" and through this, generate deeper understanding of what is involved in becoming and being an engineer. This paper reports on the research undertaken with engineers to define the EHoM and identifies some of the distinctive features of signature pedagogies as they might be applied to engineering education. It concludes by outlining future research to further validate and define habits of mind and signature pedagogies for engineering.
\end{abstract}

Index Terms-engineering education, engineering habits of mind, growth mindset, signature pedagogy.

\section{Background To The Study - The Need For More ENGINEERS}

The acute shortage of engineers is recognized worldwide and the challenge to engineering education has traditionally been portrayed as a supply and demand problem, leading to numerous initiatives to secure the "pipeline", or increase the flow of engineers from school science to post16 Science, Technology, Engineering and Mathematics (STEM) careers. In England, for example, one response to the problem has been to increase the number of specialist secondary (14-18 years) schools offering education specifically aimed at developing young people's interest and ability to engage in STEM subjects and other vocational subjects [1]. Despite some recent encouraging successes with more young people gaining qualifications in mathematics, physics and science that enable them to study STEM at higher levels, this progress is still fragile, with significant drop off among those studying physics in the latter years of schooling [2]. Furthermore, many engineering graduates leave the profession once qualified, choosing to work in non-STEM industries [3].

It is ironic that this recruitment challenge persists at a time when engineering has never been so diverse or offered so exciting a career [4] but engineering still seems unable to shake off its outdated image. This may be because attitudes towards engineering are developed in indi- viduals at a very early age and obsolete public perceptions about the nature of engineering as a career communicated by family and teachers result in children as young as ten believing that this is not a career to aspire to. This lack of a positive self-identity with STEM subjects leads to an early rejection of science and mathematics as subjects worth studying. While the factors affecting the selection of and achievement in STEM subjects are complex, there is now a considerable body of evidence which looks beyond earlier assertions that young people are simply not willing to study difficult subjects and identifies a number of reasons as to why so many young people hold a rational belief that engineering "is not for me" [2], [5], [6]. What if many young people intuitively think and act like engineers but then find that there are progressively fewer opportunities in schools for them to learn in a manner that suits their aspirations and they become alienated from the subject? What if schools and colleges, with some honorable exceptions, are still teaching in ways which work well to discourage all but the most persistent young proto-engineers?

This premise suggests that the simple "pipeline" metaphor is not very helpful in attempting to address the lack of engineers, so we proposed that the challenge could be reframed as a learning challenge and explored through the lens of habits of mind [7]. We hypothesised that the shortage of engineers could, to some extent, be due to a lack of understanding about how engineers actually think. Maybe teaching more young people to "think like an engineer" could be a more fruitful way of tackling the challenge of capturing their interest. In approaching the research in this way, we posed questions such as: What do engineers do? How do they think? How do they approach problems? How is what they do similar to but different from how a scientist or a mathematician sees the world? What does an engineer have in common with an artist or a designer or a technologist or a politician or a team sports player? What, in short, goes on in the mind of an engineer when he or she is in full flow doing engineering? These queries led us to focus on the following research questions:

- How do engineers think and act?

- How best can the education system develop learners who think and act like engineers?

Considering the huge breadth of the engineering sector we thought that gaining consensus on these issues might be impossible, but we found that there was substantial consensus as to how engineers think and act distinctively. We refer to these specific ways of thinking and acting as engineering "habits of mind" [EHoM]. Employing an 


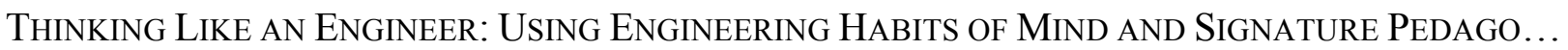

iterative process of study and conversations with practising engineers and educators we identified six EHoM, which include "systems-thinking", "adapting", "problemfinding", "creative problem-solving", "visualising", and "improving". We then considered the learning and teaching approaches that might be used to cultivate habits of mind using the lens of "signature pedagogy" [8]. We identified two specific approaches, the "engineering design process" and "learning from professionals", that we believe could have the hallmark of a signature pedagogy for cultivating engineering habits of mind. This paper explores our process of discovering and defining engineering habits of mind and discusses ways in which a focus on teaching "thinking like an engineer" might reinvigorate the debate about optimising engineering education at all levels to create the new kind of engineer professionals the world needs.

\section{RESEARCH APPROACH}

We adopted a mixed methods approach using qualitative interviews, an online survey and discussions with an expert panel. The pragmatic philosophy underpinning mixed methods and its recognition of the value of using data gained from contrasting methods [9] aligned well with our research funder's wish to incorporate multiple perspectives and explore real-world approaches to learning. We reviewed the literature relating to habits of mind in engineering, mathematics and science and searched for case studies at all levels of education in which innovative pedagogies had been used to develop habits of mind. As educationalists ourselves rather than engineers, we also sought to increase our insight into the profession by reviewing engineering definitions and creating word clouds from these. We mapped terms from specifications such as UK-SPEC [10] and EUR-ACE [11] and also reviewed websites offering young people insight into engineering careers, such as Tomorrow's Engineers [12]. From these sources we developed our initial list of six potential EHoM to explore with engineers through the interviews.

We identified a purposive sample of individuals to invite to interview, drawn from a list provided by the UK Royal Academy of Engineering (the Academy). From an original list of 28 names we invited 16 individuals to participate in a telephone interview lasting around 35-40 minutes. Eight agreed to be interviewed and a further four provided responses to our questions by email. The interviews were recorded and transcribed. Three respondents were familiar with the primary education sector, four with secondary, three with technical/vocational education and four with higher education. Some had knowledge of more than one education sector. Eight were male; four were female. The disciplines with which they were familiar included chemical, mechanical and automotive engineering, physics and design and technology. There are of course many other engineering disciplines, for example, software engineering and medical engineering, but the small scale scope of this research did not enable us to include a wider range.

The interviews evaluated the validity of each EHoM with reference to different education sectors and engineering disciplines and also explored respondents' perceptions of the characteristic ways of thinking used by engineers. Open ended questions encouraged them to tell their own stories about their path to becoming an engineer or engi- neer educator and the role of their own education in that process.

We gained further insight into EHoM and effective pedagogies by convening an expert panel of practising engineers and engineer educators, again with the help of the Academy. This group met on two occasions with 23 individuals participating in the first session and 12 in the second. Since our aim was to value what is already working well in engineering education and to build relationships with experienced professionals, we adopted an appreciative inquiry [13] approach to these discussions. In the first session we discussed our EHoM model and invited participants to share examples of effective pedagogies. In the second session we invited participants to discuss our draft report and help us formulate recommendations based on our findings. Individuals who contributed to the research were acknowledged in the full report and their names are included in that publication, but for this paper anonymised quotes have been used from the interviews and survey to illustrate themes identified.

In order to explore perceptions of our EHoM with a wider audience, we developed a questionnaire survey that was circulated by the Academy to its member groups involved in education activities and completed online. We were not able to draw any statistical inferences from the quantitative data, but the qualitative comments were useful for augmenting the interview data. The final stages of our research involved matching learning and teaching methods recognised as effective in a wide range of disciplines to our validated EHoM. This process was allied to conceptual development by the research team of a broader pedagogical framework within which these might fit, included within which was the concept of signature pedagogies.

\section{HABITS OF MIND}

\section{A. Background to Habits of Mind}

Habits of mind (HoM) is an expression used by psychologists such as Resnick [14] to describe aspects of intelligence. The term was adopted by educationalists Costa and Kallick [7] who identified sixteen HoM which, taken together, describe what "smart people do as they go about their lives successfully dealing with whatever unexpected problems are thrown at them". They also suggested that the role of teachers might change if they were deliberately trying to encourage the development of HoM in learners. In the UK, Claxton created an approach to teaching and learning called "Building Learning Power" (BLP) [15] which has seventeen HoM. More recently we have drawn from these three traditions to create and validate an extended model of practical learning which blends habits and frames of mind [16]. We have also researched the development of creative habits of mind [17]. This earlier body of research became a proof of concept for focusing on a discipline such as engineering and seeking to identify its characteristic HoM.

A critical distinction between habits of mind and other popular ways of describing individual learning differences, for example learning styles or non-cognitive skills, is that habits of mind, or learning dispositions, are not fixed traits, they are capable of development. The view that learning performance can be improved through deliberate effort and practice is supported by Dweck, who contrasts the "growth mindset" of those who believe that 
Thinking Like An Engineer: Using EngineERING Habits of Mind AND Signature Pedago...

their abilities can change, who work hard, try different strategies when they get stuck and see failure as an opportunity to grow, with the "fixed mindset" of learners who have come to believe that intelligence is fixed and that abilities cannot be developed [18].

\section{B. Original conception of Engineering Habits of Mind}

Drawing on our broader experience of HoM, we investigated the extent to which they are used in engineering pedagogy and also within the teaching of its associated disciplines of mathematics and science. In the USA, engineering is now included as a specific subject within the school curriculum at primary and secondary levels in many states and educators have drawn on the HoM tradition to consider which HoM might be at the core of engineering. In particular, a major review of engineering education within K-12 primary and secondary education has called for curriculum development to be underpinned by the promotion of six EHoM [19].These six are "systemsthinking", “creativity", "optimism", “collaboration", "communication" and "attention to ethical considerations". Thinking in Australia also supports the idea that engineers need to be lifelong learners and that current educational approaches need to change [20].

\section{The contribution of Mathematical and Scientific Hab- its of Mind}

By the time engineering habits of mind were being considered, interest in habits of mind in mathematics and science had already emerged, fuelled by concern about negative public perceptions of these subjects and their role in society. In discussing the contribution of these subjects to solving important real world problems, scientists, mathematicians and educationalists identified a mismatch between what scientists and mathematicians actually do and what gets taught in school. One way of resolving this was suggested by Cuoco, Goldenberg and Mark [21] who distinguished between real-world mathematics and what happens in schools. They then explicitly refocused on the teaching of mathematics as the cultivation of mathematical habits of mind (MHoM), or the ways in which mathematicians think about problems, rather than on the mathematical content which is taught. Cuoco and colleagues identified a generic set of MHoM together with more specific subsets for geometry and algebra. They imagine mathematicians as "pattern-sniffers", "experimenters", "tinkerers", "visualizers" and "conjecturers".

There has been parallel thinking about scientific habits of mind (SHoM). Çalik and Coll [22] evaluated various approaches to the selection and definition of key SHoM. Their selection proved to be reliable and useful as a predictive tool in various contexts and included habits of mind such as "open-mindedness", "scepticism", "objectivity" and "curiosity". Leager [23] stresses how teachers can overtly develop SHoM in the classroom by modelling the attributes of curiosity, openness and scepticism.

\section{Updated Engineering Habits of Mind}

From this review of existing research and practice we developed our own EHoM to evaluate with our participants. We retained six overall, but adopted only one of the American terms outright, systems-thinking. We excluded the other five American terms, although important, as being too generic and substituted more specific EHoM by drawing on the detailed descriptions of the American terms and on the mathematics and science HoM which appeared to us to overlap with the EHoM. Our six EHoM are described in Table I. Of course, in addition to our specific EHoM, there are other powerful learning dispositions such as curiosity, optimism, resourcefulness, resilience and reflection, which engineers, like all professionals, need for lifelong learning.

TABLE I.

ENGINEERING HABITS OF MIND DESCRIPTIONS

\begin{tabular}{|l|l|}
\hline $\begin{array}{l}\text { Systems- } \\
\text { thinking }\end{array}$ & $\begin{array}{l}\text { Seeing whole, systems and parts, and how they } \\
\text { connect, pattern-sniffing, recognising interdependen- } \\
\text { cies, synthesising }\end{array}$ \\
\hline $\begin{array}{l}\text { Problem- } \\
\text { finding }\end{array}$ & $\begin{array}{l}\text { Clarifying needs, checking existing solutions, inves- } \\
\text { tigating contexts, verifying }\end{array}$ \\
\hline Visualising & $\begin{array}{l}\text { Move from abstract to concrete, manipulating mate- } \\
\text { rials, mental rehearsal of physical space and of } \\
\text { practical design solutions }\end{array}$ \\
\hline Improving & $\begin{array}{l}\text { Relentlessly trying to make things better by experi- } \\
\text { menting, designing, sketching, guessing, conjectur- } \\
\text { ing, thought-experimenting, prototyping }\end{array}$ \\
\hline $\begin{array}{l}\text { Creative } \\
\text { problem- } \\
\text { solving }\end{array}$ & $\begin{array}{l}\text { Applying techniques from other traditions, generating } \\
\text { ideas and solutions with others, generous but rigorous } \\
\text { critiquing, seeing engineering as a "team sport" }\end{array}$ \\
\hline Adapting & $\begin{array}{l}\text { Testing, analysing, reflecting, re-thinking, changing } \\
\text { (physically and mentally). }\end{array}$ \\
\hline
\end{tabular}

IV. ENGINEER's PERCEPTIONS OF ENGINERING HABITS OF MIND

When we interviewed our engineers, we identified considerable consensus among them about the overall passion that drove them when undertaking engineering projects. When asked the question "What do engineers do?" our respondents repeatedly stressed that the desire to "make things that work" or make things "work better" was the driving force behind what made them become engineers:

"Great engineers constantly challenge the 'norm' and are always looking for improvements and innovation in everything they do. They are never fully satisfied with a product or outcome and will try and modify and improve what they have designed or produced to make it better." (Respondent 2:34)

We also found considerable consensus among all respondents that our six EHoM were appropriate descriptors for the characteristic ways in which engineers think and act when faced with challenging problems relating to making and improving things. However, despite an overall agreement on the importance of all six, there were some differences of opinion on the relative importance of each at different education levels.

Systems thinking was universally supported as an important EHoM but was felt to be particularly difficult to cultivate, perhaps being of most importance the more advanced the level of engineering became:

"The idea that everything you do sort of builds to making you into a rounded, capable person who can link all the knowledge together is the one that perhaps we could work on." (Respondent 8:57).

Problem-finding was also regarded as a sophisticated EHoM and more likely to be exercised by experienced engineers or by learners after they had successfully built up a repertoire of approaches to problem solving based on given problems: 
"I want them to solve the problems that I presented and then build up a sort of database on that experience that will help them find problems later on." (Respondent 3:70)

Some respondents wondered whether "finding" was the best term, suggesting "formulating" or "framing" as alternatives. But the majority agreed that separating out problem-finding from problem-solving was important.

Visualising was regarded as an important EHoM for all education sectors to cultivate, since it enabled an engineer to take an abstract idea and communicate a practical solution in a more concrete form:

"To be able to take something abstract and then make it into a practical solution, you have to have that sort of visualisation to be able to do that." (Respondent 4:38)

Improving, or a relentless drive to improve products, was regarded as a core characteristic of an engineer. It was the result of constant tinkering and experimenting to find better solutions:

"They [engineers] are never fully satisfied with a product or outcome and will try and modify and improve what they have designed or produced to make it better." (Respondent 2:34-36)

However, this was not just tinkering for the sake of it; the engineer's underlying desire to improve was driven by a social conscience to help society move forward:

"It's all about making things easier for people's lives...whether it's a product that you're making simpler to use, or making something quicker to use... its improving people's lives." (Respondent 4:42)

Creative problem-solving provoked strong reactions. There were those who thought that it was the most important EHoM:

"Creative problem solving is the real standout there. That's my number one." (Respondent 10:78)

This was predominantly the perspective expressed by those engaged in primary education, while those involved in post-compulsory engineering education expressed doubts, not about the importance of problem solving itself as an EHoM, but about preceding it with the adjective "creative". These respondents were in no doubt about the importance of creativity in engineering, because:

"You often have to bring ideas from different disciplines and different divisions to solve the problem." (Respondent 1:50)

However, others thought that being creative might be in conflict with the requirements to consider previous solutions to problems and to adhere to recognised standards:

"It is common in engineering to use concepts that are not original. Engineers would not normally think that they were being creative unless at least one of the options involved a new concept. Therefore the qualification of problem solving by the adjective creative excludes a lot of engineering work." (Respondent 11:87)

This idea that being creative might act as a barrier to becoming an engineer is not supported elsewhere. The need for creativity to have greater prominence in the education of engineers is stressed, both in order to secure new and innovative solutions to challenging world problems [24] and also to allow for the incorporation of active learning pedagogies more commonly found in the creative disciplines and the liberal arts education [25]. In trying to find a path through this debate, another respondent re- ferred us to the distinction between big- $\mathrm{C}$ creativity and little-c creativity, as identified by Craft [26] in her exploration of creativity in the education of young children. Big-C creativity is exercised by the high creators whose ideas do radically change the domains of knowledge, but little-c creativity is operationalized by individuals who find their way around problems using what Craft calls "possibility thinking". She also uses the term "problem finding" to describe this type of creative activity, where the outcome may be innovative to the individual, although not in the wider world. So, while we have included "creative" with problem solving for now, we recognise that further discussion around this EHoM is required, since it clearly raised an important point about engineers' perceptions about engineering:

"I believe engineering to be much more of an "art" than we commonly recognise. Experience and intuition complement scientific knowledge and underpinning. There is quite a contrast to the approach to a problem taken by a competent engineering professional, to that taken by one a scientist." (Survey respondent 40)

Adapting is an EHoM about which respondents had mixed views. Primary level educators thought that it was too sophisticated a concept for entry level engineers and could only be cultivated after they had some experience to draw on to make judgements. However, experienced engineers and those within higher education thought that it was an important EHoM:

"[Adapting] is very important; a lot of engineering is doing the same things only slightly differently." (Respondent 5 :107)

Several respondents suggested that it was unlikely that all our EHoM would be found in one engineer and stressed the overall importance of the team in successful engineering projects. Nevertheless, they argued that engineers should be sufficiently self-aware to know when it was appropriate to draw on the skills of others in the team:

"I think good engineers, certainly in a team, can do that. They can do what they have to do but they can also sort of observe themselves doing it and ask, "Am I using the appropriate skills at the appropriate points in all of this?" (Respondent 8:71)

Engineers, as MacLeod puts it, rarely operate in one mode only, but are able to move between "two modes of thinking" [27] and as a consequence of these discussions we realised that much of the engineer's world is necessarily about holding a series of tensions in balance, for example, between using creativity to invent new ways of doing things and using logic to make things work:

"I think any very good engineer can do both, to look at something quite creatively and then put it into some sort of logic to actually get to an end solution." (Respondent 4:24)

Having found consensus on our six EHoM, we chose to represent our model in Fig. 1 as series of concentric circles because it allowed us to articulate at the core of the model the driving force of engineering - "making stuff" and to distinguish between two sets of habits of mind important to engineers, placing the more specific EHoM closer to the core, but recognising the relevance of a broader set of learning habits. 


\section{PAPER}

\section{Thinking Like An Engineer: Using EngineERING Habits of Mind And SignAture PedagO...}

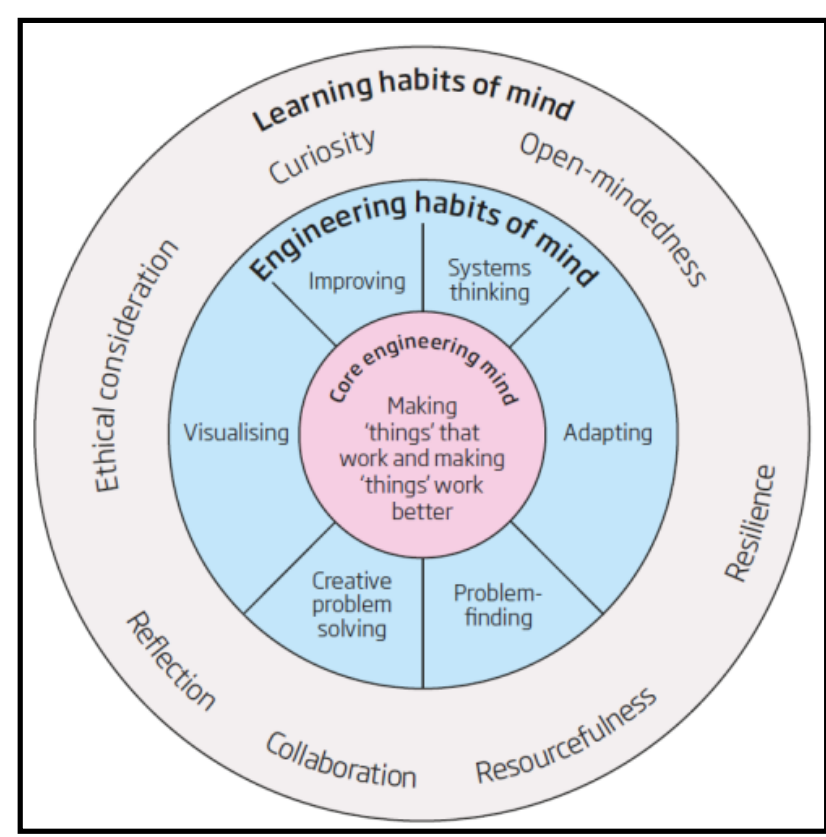

Figure 1. Engineering Habits of Mind

We recognise that the term "making" refers principally to traditional engineering disciplines and also that engineers engage in all sorts of activity which may not involve making things [28]. However, even engineers such as chemical or software engineers who do not "make" physical products as such, are involved in the sub-elements of making such as designing and implementing. It is this extended definition of "making" to which we attach central importance.

\section{IMPLICATIONS OF EHOM FOR REDESIGNING ENGINEERING EDUCATION}

\section{A. Teaching for developing habits of mind}

Having identified our six EHoM, we looked for examples of engineering teaching that might be best suited to developing them. In our full report [29] we provide examples where innovative pedagogies likely to develop EHoM have been used in schools, colleges and, in particular, in universities, where initiatives such as CDIO, (ConceiveDesign-Implement-Operate) or methods such as problembased leaning (PBL) and project-based learning $(\mathrm{PjBL})$ offer great potential for developing EHoM. However, good examples, especially at school level, are limited, so we explored the extent to which it might be possible to build on these existing methods by focusing more precisely on the kinds of pedagogical approaches which seem most likely to cultivate learners who might really think and act like engineers.

Teaching for developing habits of mind does not add more content to the curriculum but it does require teachers to adopt a different pedagogic approach. Teachers need to build up their own and their learners' understanding of the relevant habit of mind and its components so that they recognize the habits when students are using them. They need to cultivate a learning climate that demonstrates that the use of EHoM is valued, for example through modelling its use, through assessment criteria or other reward structures. They then need to select pedagogies likely to encourage EHoM through facilitating their practice.
Two examples illustrating how being more specific about the language of EHoM might provoke a shift in thinking about teaching can be seen in recent publications. Macdonald [2] suggests that the use of engineering competitions for motivation in classrooms is not helpful for engaging girls, who are likely to lose out to boys because they spend longer on the task getting precise results, whereas boys are happy to "get the jist", move on to the next task and finish sooner. In fact, the girls are displaying the important EHoM of "improving", but this is not being recognized or valued. A further indication that the important creative aspect of EHoM is not being nurtured and valued in those learners that display it, is that the top two occupations that engineering graduates entered in 2011/12 in non-STEM sectors were in sales and in artistic, literary and media occupations [3]. This point is amplified by Stephanie Fernandez in her blog [30] when she suggests that although engineers are by nature more introverted, they need to "lose their inhibitions" and get better at promoting what they do, in order to recruit more engineers. In fact, engineers have probably been successful though the education system by being introverted and have not been challenged to change their habits, nor have extroverts been seen as "engineering material", which suggests the system needs to change as much as engineers.

\section{B. Three approaches to engineering pedagogy}

By pedagogy we include both the specific methods and the wider context in which teaching and learning used takes place:

"Pedagogy... is the science, art and craft of teaching. Pedagogy also fundamentally includes the decisions which are taken in the creation of the broader learning culture in which the teaching takes place and the values which inform all interactions. " [31]

We suggested that there are three approaches through which engineering educators might make more effective decisions about teaching and learning methods to cultivate learners who really think and act like engineers:

- consider the overall sense of what engineers do and adopt an holistic, or "signature" pedagogy which seems, on balance, likely to "make" engineers;

- look at the six EHoM individually and see what educators have found to be most helpful in cultivating each of these;

- approach the challenge from a different perspective by looking at teaching methods which, in other subjects or vocational pathways, seem likely to be transferable [29].

In this paper we give further consideration to the first of these approaches, the concept of signature pedagogies for engineering education.

\section{Signature pedagogies}

Arguments in support of discipline-specific teaching practices have been growing for some time in the social sciences and humanities [32] and have also been emerging in disciplines which prepare students to become members of a professional community [33], [34]. Disciplinespecific teaching recognizes the specific nature of knowledge in the discipline and the characteristics of what it means to be a professional in that area. This concept of "signature pedagogy", which Shulman [8] defined as "the types of teaching that organize the fundamental ways in 


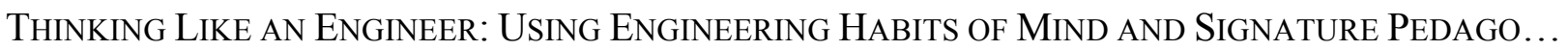

which future practitioners are educated for their new professions" aligns well with our proposal that engineers have a specific way of thinking that should influence engineering pedagogy. In stressing the importance of signature pedagogies, Shulman goes on to suggest that:

"Signature pedagogies make a difference. They form habits of the mind, habits of the hand and habits of the heart... signature pedagogies prefigure the culture of professional work and provide the early socialization into the practices and values of a field. Whether in a lecture hall or a lab, in a design studio or a clinical setting, the way we teach will shape how professionals behave." [8].

In seeking to explain signature pedagogies more precisely, Shulman argues that they have three levels, or structures - surface, deep and implicit. At a surface level a tutor would consider specific and discernible acts of teaching and learning, such as demonstrating, questioning or group work. At a deeper level, the use of these methods would require understanding of the assumptions made about how to best convey and teach the content to students, for example, through practical application rather than didactic exposition. At the implicit level there would be a group of desirable beliefs, attitudes, values, and dispositions that are important to the profession, such as integrity and empathy, which also require attention.

The value of a signature pedagogy for professional learning lies in its power to enable the learner both to become and to be a professional. The experience of a signature pedagogical approach reinforces professional formation and professional preparedness. One way in which it achieves this, according to Shulman [35] is to emphasize "the visibility of person and process". A signature pedagogy ensures that students and their thought processes are made visible, as for example, when law students are expected to build on the comments of their fellow students to present their own view on a case, or medical students are expected to contribute to discussions about patients during "clinical rounds". This visibility is associated with both engagement and accountability in the education process and also in the professional culture.

However, a particular pedagogy should not qualify as signature just because it has been in use within the discipline for a long time. It is important for signature pedagogies to adapt to changing circumstances, either in response to professional requirements or to new teaching methods since, if they become too entrenched they risk fostering silo mentalities within professions that may inhibit professional inter-collaboration. On the other hand, a signature pedagogy such as problem based learning that is a well-established method in many disciplines could facilitate professionals working effectively on multidisciplinary teams [36]. Shulman himself suggests that signature pedagogies should be reviewed from time to time to ensure that they are still appropriate for fostering the desired habits of mind that align with current professional requirements [37]. Opportunities to review a signature pedagogy may be prompted by changes in professional practice, as, for example, within the medical profession, where the increasing importance of the ability to communicate effectively with patients and their families has had an impact on the nature of discussion between tutors and students during clinical rounds.

Alternatively, changes in the education process, such as new teaching methods afforded by technology, can prompt review of the signature pedagogy. For example, the design studio plays an important part in professionalizing architecture students and the one-on-one discussion that each student has with the tutor plays an important role in socializing students into a profession that values critical self-evaluation. However, as Crowther [38] notes, this approach can be undermined by tutors who maintain a traditional hierarchical student-tutor role, which is less likely to instil an attitude conducive to developing professional relationships in the office environment. He suggests how online discussion embedded within the pedagogy of the design studio process could enhance the "discussion and debate" elements of studio pedagogy and potentially limit some of the shortcomings of the face to face approach. In STEM disciplines, Crippen and Archambault [39] demonstrate how Web-based tools such as "mashups" can be used to refresh inquiry based learning in science and Passey [40] explores how new technologies could be used to update signature pedagogies in the context of teaching mathematics.

Having identified specific disciplinary habits of mind for engineering, the concept of signature pedagogy would appear to offer interesting possibilities for reviewing pedagogic approaches in engineering education that place greater emphasis on the formation of professional characteristics that are underpinned by EHoM. With other examples of signature pedagogies in use in some STEM subjects, it is surprising that there has been such limited articulation of signature pedagogies in engineering, which has professional formation as one of its primary aims. However, our respondent engineers reinforced the fact that, in their view, the engineering curriculum currently does not do enough to develop EHoM:

"The engineering approach is as much driven by attitude/EHoM as by knowledge. If this is so, then it needs to be a main feature of engineering education. Good attitudes need to start as early as possible. Knowledge assimilation can wait a bit." (Respondent 11:5)

This encouraged us to consider some candidate signature approaches which are examined in the next sections.

\section{Signature pedagogies for engineering}

Shulman's original research included an investigation into signature pedagogies in engineering. In order to illustrate how a traditional teaching method can undermine the development of engineering habits of mind, he describes a typical lecture in fluid dynamics in an imaginary university engineering school. The lecturer only briefly greets the class before turning to the board on which he furiously writes mathematical equations. All the seats in the lecture room face the front. From time to time the lecturer goes through the motions of checking that students understand him, but such moments are perfunctory. There is little interaction between students and students or students and the lecturer and no reference to the challenges of engineering practice. There is, Shulman suggests, "little sense of the tension between knowing and doing"; what he is seeing is not the "signature" of engineering but of one very specific kind of mathematics.

Shulman contrasts the engineering lecture hall with an imaginary design studio. Here students gather around work areas with physical models and on-screen designs. They are experimenting and building things, frequently commenting on each other's work. It is not easy to see who the teacher is! 
"Instruction and critique are ubiquitous in this setting, and the formal instructor is not the only source for that pedagogy." [8]

The second of Shulman's imaginary educational settings is much closer to the "signature" of an engineering experience which might cultivate the six EHoM described earlier.

We now explore two pedagogical approaches that might be designated "signature" for engineering. The first of our candidates is one also recognized by Shulman, the engineering design process, which we explore in conjunction with problem/project based learning and the $\mathrm{CDIO}^{\mathrm{TM}}$ Initiative. The second is learning from professionals. These two are highlighted because, although primarily associated with higher education, they have the potential for application across all sectors of education from primary school onwards.

\section{E. The enginering design process as a signature pedagogy for engineering}

Shulman argues that the design process has the potential to become a "family" signature pedagogy for engineering even after undergraduates have moved on from fundamental courses in mathematics and physics into their specific engineering disciplines:

"Because even though there are certain fundamental courses in math and physics .., the undergraduate preparation of engineers begins to break apart fairly early as they move to electrical and mechanical, and civil .... And yet, in the design programs where they're really doing practice, I think there are a lot more family resemblances in the signature pedagogies, even though what they're designing may range from circuits to robotics, to models of bridges or airplanes." [35]

Shulman's proposition reflects our finding, in which support for the six EHoM was consistent across a range of engineering disciplines. While there are many variations and degrees of complexity inherent in the design process, we selected an example from NASA [41] to illustrate our argument, as shown in Fig.2, as it has a surface structure that can be easily grasped at all phases of education.

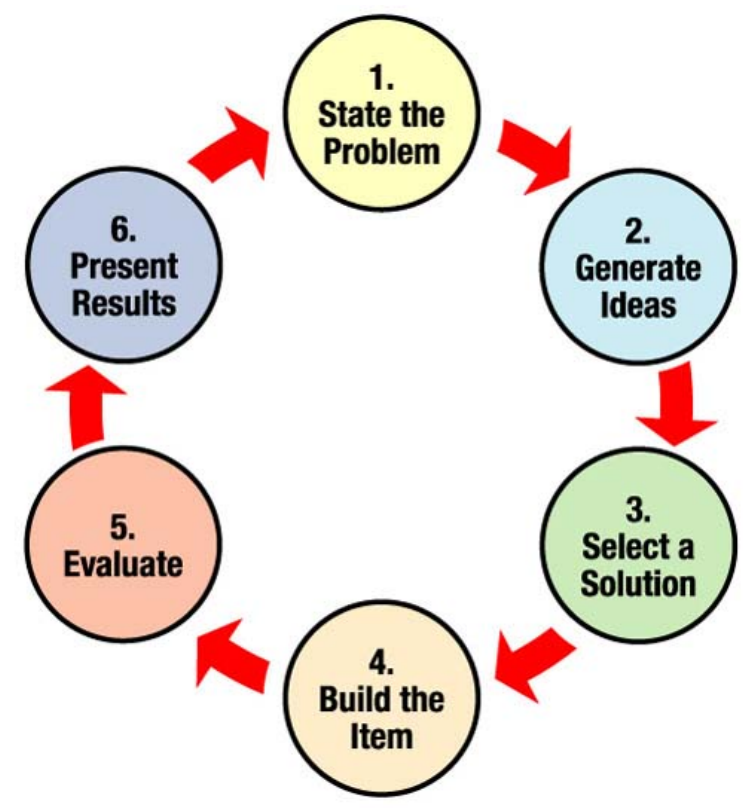

Figure 2. NASA Engineering design process
It could also be argued that its deep structure, which emphasizes action through its focus on building and evaluating, reflects the core engineering signature at the center of our model of EHoM - "making things that work". Furthermore, by taking the student through the process of generating ideas and selecting a solution, it offers opportunities to develop core professional attitudes related to holding tensions between EHoM in balance, as identified by one of our respondents:

"Going through that problem solving process, you're constantly looking to see whether you could improve. But then the practical side has to kick in to say, "Okay, you gone about as far as you can, given the budget you've got or the time you've go or whatever, that you really have to, you know, put a lid on it now, and you have to come to some formal conclusion." (Respondent 3: 80)

The curriculum structures often associated with the introduction of the engineering design process are those that support active leaning, such as problem based learning (PBL), project based learning (PjBL) [42], or ConceiveDesign-Implement-Operate (CDIO) [43]. There are similarities and differences between PBL and CDIO; they both aim to enable students to develop process and professional skills such as self-directed learning and problem solving, but whereas PBL was originally developed in disciplines such as medicine and law and then applied to engineering, CDIO was developed from within the engineering community to reform engineering education by presenting an alternative to the traditional linear engineering degree curriculum. From its beginning in the late 1990s, CDIO is now a global organization and possesses a formal membership structure including a Council which has oversight of its Syllabus and Standards. PBL is practiced by a multitude of open communities in many disciplines as well as engineering and even where it is practised in engineering it is frequently found being used concurrently with traditionally taught courses [44].

It is worth considering whether PBL and CDIO might be signature pedagogies in their own right but on reflection there are specific factors that may exclude them. Both models encompass the surface structure of signature pedagogy, with teaching activities such as projects and group work. A deep structure is also evident through the significance they both place on experiential and social learning rather than transmissive teaching approaches, through which students construct their own knowledge rather than passively listening to lectures, and also through integrated learning of disciplinary knowledge and professional engineering skills. The implicit level is represented overtly in the CDIO Standards which ensure that learning outcomes include personal skills and professional attributes similar to EHoM, such as systems thinking. The on-going examination of CDIO with reference to the learning sciences is also worth noting [45]. The origins of PBL are situated in the growth of student-centered learning in the late $1960 \mathrm{~s}$ and 1970 s and one of its fundamental principles is interdisciplinary learning to ensure that problems encountered by students are situated in the real world to prepare them for professional practice [46]

However, the CDIO Initiative is referenced specifically to university level education and PBL covers a wide diversity of educational practices. Furthermore, they both need to be considered in terms of their resource requirements, so fully employing them may well be inappropriate for schools and colleges to consider. Nevertheless, the 
Thinking Like an EngineER: Using EngineERING Habits of Mind And Signature Pedago...

engineering design process could be used at all levels of education to contextualize student work in science and mathematics and foreground engineering practices rather than mathematics and science practices, as demonstrated by Berland [47], and by English and King [48]. For these reasons, we suggest that the engineering design process warrants further investigation as a potential "signature pedagogy" for engineering whichever curriculum structure is used to introduce it.

\section{F. "Learning from professionals" as a signature pedagogy for engineering}

Mentoring of student engineers by STEM professionals who act as role models is an important element of engineering education and can be observed in further and higher education through, for example, the use of "live" projects with industry, placements or mentoring schemes [49]. Furthermore, at school level, as the popularity of formalized employer networks such as the STEM Ambassadors scheme [50] illustrates, engaging engineers to work with teachers in extra-curricular clubs or projects is a widespread method of introducing young people to the world of engineering and in stimulating career aspiration. It would therefore appear that it may be possible to position "learning from professionals" as a signature pedagogy, since it clearly has an implicit level structure promoting desirable beliefs, attitudes, values and dispositions that are important to the profession. However, the variety of ways it can be employed, either within the curriculum or outside it, may limit its potential to become fully recognized as a signature pedagogy unless it develops more fully defined surface and deep level structures. It may be useful to consider how this might be achieved by examining the use of professionals in the classroom in another discipline, as the following example in creative arts illustrates.

A research project in the creative arts which investigated the potential for learning from creative practitioners and incorporating their practices from the world of work into primary and secondary education identified a number of distinctive characteristics about the pedagogies used by these practitioners that could be described as "signature" [51]. The pedagogies used by the practitioners not only introduced and taught specific subject knowledge, but also embodied "professional norms, mores and conventions". Despite the fact that the practitioners engaged in different ways with the schools, the researchers were able to identify common themes that could be called "signature". Notions of creating a "third space" within the school, the hybrid roles of practitioners encompassing both practice and teaching, an openness within the school to involving the external community and flexibility of time, were all features that underpinned creative signature pedagogies which challenged the traditional pedagogies normally found in the schools. The project acknowledged that signature pedagogies were normally associated with higher education but noted sufficient resonance between what happens in universities and the ways in which the creative practitioners worked with children to justify their interest in transferring it from one sector to another. This work therefore offers a model for examining how "learning from professionals" could be developed as a signature pedagogy for engineering and be embedded more fully within the curriculum rather than remaining primarily outside it in after-school clubs.

\section{DISCUSSION}

As we noted at the beginning of this paper, developing an identity as an engineer is an important factor underpinning the motivation of a young person to pursue engineering as a career. However, Berliner [52] argues that the pedagogy of a discipline influences not only how it is perceived as a subject of study but also how attitudes towards the profession are formed. If this is the case, pedagogies for STEM subjects that only seek to develop subject knowledge and do not also address the habits of mind required to think and behave like an engineer, will not change the image of the profession; it will remain as invisible as Trevelyan [53] claims it is now.

It is interesting to compare our proposition to strengthen engineering education through overt recognition and inclusion of EHoM with the proposal that combining the study of engineering with liberal arts might offer a path for reinvigorating engineering education. Bucciarelli and Drew [54] suggest that traditional undergraduate engineering education should be broadened to include liberal studies subjects that would provide a firmer grounding in critical thinking, creative design and social responsibility required by professional engineers in the real world. The value of this argument and the urgent need to reform traditional engineering education are recognized, however, commentators point out that university structures would need to change significantly to accommodate the proposed integrated course design [55] and that exceptional teaching expertise would be needed to accommodate interdisciplinary teaching [56]. An alternative vision is offered by an engineering course that take a more expansive approach to situating engineering "as an occupation" within the technical engineering core by directing students to reflect on their personal and career goals [57]. The core components of this course offered by Rensselaer Polytechnic Institute include interdisciplinary design studio sequences in which students tackle practical problems, reflect on their learning and interact with instructors on a more democratic level appropriate to encouraging their identity as beginning professionals. This course design has more in common with the signature pedagogies for cultivating EHoM, but we would go further to suggest that EHoM can be implemented by existing faculty within current subject content and course designs. The key challenge however, as with successfully embedding any educational innovative, is to achieve a change of mindset among the teachers responsible for delivering it.

It should be acknowledged that ours was a small scale research study; therefore the next stage of our research aims to build on our initial findings and review the validity of the six EHoM and their ability to influence attitudes towards engineering in different educational contexts. To achieve legitimacy in educational change it is important to involve all stakeholders in the dialogue [44]. Consequently we are working with teachers in schools and colleges to support them as they cultivate EHoM by teaching STEM subjects using signature pedagogies, such as the engineering design process and learning from professionals, but also through other approaches aimed at explicitly embedding EHoM concurrently with subject content. We are exploring the ways in which EHoM can most effectively be cultivated in learners by teachers' use of strategies such as role modeling and overt recognition and reward for the demonstration of EHoM, and how EHoM might permeate the whole culture of the school or college. Our aim is to 
Thinking Like an Engineer: Using Engineering Habits of Mind And Signature Pedago...

develop case studies illustrating this practice and to map examples of how EHoM can be introduced through the separate subjects that contribute to STEM within the English National Curriculum, as for example, Loveland and Dunn [58] have achieved in mapping the American engineering habits of mind to national frameworks and standards in K-12 education for technology and science.

\section{CONCLUSION}

Our research re-conceptualized the traditional way of dealing with the shortage of engineers by identifying six habits of mind that describe the specific way of thinking used by engineers when tackling engineering problems: systems thinking, problem-finding, visualising, improving, creative problem-solving and adapting. The endorsement of these six EHoM by engineers provided evidence for us to suggest that the problem with the current education system at all levels is that it does not do enough to cultivate the habits of mind required by today's engineers.

We then proposed some ways in which pedagogies for engineering might be redesigned in the light of these EHoM, in particular by considering the value of the signature pedagogies concept. We suggest that those involved in engineering teaching and learning need to consider redesigning engineering education at all levels and start from the premise that they are trying to cultivate learners who think like engineers, and we have suggested that a clearer articulation of the signature pedagogies of engineering may support this aim.

\section{ACKNOWLEDGMENT}

The authors would like to thank Dr Lynne Bianchi and her colleagues at the Science and Engineering Education Research and Innovation Hub at the University of Manchester, UK for their on-going critical friendship and participation in the next stage of this research.

\section{REFERENCES}

[1] K. Baker, 14-18-A New Vision for Secondary Education. London: A\&C Black, 2013.

[2] A. Macdonald, "Not for people like me?" Under-represented Groups in Science, Technology and Engineering. Bradford: WISE, 2014. Available: http://www.wisecampaign.org.uk/education/notfor-people-like-me

[3] Engineering UK (EUK), Engineering UK 2014 Synopsis, Recommendations and Calls for Collaborative Action. London: Engineering UK, 2014. Available: http://www.engineeringuk.com/re search/Engineering_UK_Report_2014/

[4] Engineering the Future, The Universe of Engineering: A Call to Action. London: Royal Academy of Engineering, 2014.

[5] ASPIRES, ASPIRES Final Report. London: Kings College London, 2013. Available: http://www.kcl.ac.uk/sspp/departments/ education/research/aspires/ASPIRES-final-report-December2013.pdf

[6] F. S. Becker, "Why don't young people want to become engineers? Rational reasons for disappointing decisions," European J. of Eng. Educ., vol. 35, pp. 349-366, 2010. http://dx.doi.org/10.1080/03043797.2010.489941

[7] A. Costa and B. Kallick, Discovering and Exploring Habits of Mind. Alexandria, VA: Association for Supervision and Curriculum Development, 2002.

[8] L. S. Shulman, "Signature pedagogies in the professions," Daedelus, no. 134, pp. 52-59, 2005.

[9] R. B. Johnson and A. J. Onwuegbuzie, "Mixed methods research: a research paradigm whose time has come," Educational Researcher, no. 337, pp. 14-26, 2004. http://dx.doi.org/10.3102/ $\underline{0013189 \times 033007014}$
[10] Engineering Council, UK Standard for Professional Engineering Competence UK-SPEC. London: Engineering Council. Available: http://www.engc.org.uk/ukspec.aspx

[11] European Network for Engineering Accreditation (ENAEE), EUR-ACE Framework, Standard and Guidelines, $31^{\text {st }}$ March 2015. Available: http://www.enaee.eu/wp-content/uploads/2015/04/ EUR-ACE-Framework-Standards-and-Guidelines-Mar-2015.pdf

[12] Tomorrow's Engineers, 2015. Available: https://www.tomorrows engineers.org.uk/

[13] H. Preskill and T. T. Catsambas, Reframing Evaluation through Appreciative Inquiry. Thousand Oaks, California: SAGE Publications, 2006.

[14] L. Resnick, "Making America smarter," Educ. Week Century, Series 18, pp. 38-40, 1999.

[15] G. Claxton, Building Learning Power. Bristol: TLO Ltd., 2002

[16] G. Claxton, B. Lucas and R. Webster, Bodies of Knowledge; how the learning sciences could transform practical and vocational education. London: Edge Foundation, 2010.

[17] B. Lucas, G. Claxton, and E. Spencer, Progression in Student Creativity in School: First Steps Towards New Forms of Formative Assessments. OECD Education. Working Papers, No. 86. Paris: OECD Publishing, 2013. http://dx.doi.org/10.1787/ 5k4dp59msdwk-en.

[18] C. S. Dweck. Mindset: The New Psychology of Success. New York: Ballantine, 2006.

[19] L. Katehi, G. Pearson and M. Feder, Engineering in K12 Education: Understanding the Status and Improving the Prospects, Committee on K-12 Engineering Education, National Academy of Engineering and NRC. Washington, DC.: National Academies Press, 2009.

[20] S. Beder, "Beyond technicalities: expanding engineering thinking," Journal of Professional Issues in Eng. Educ. and Practice, vol. 125 , pp. 12-18, 1999. http://dx.doi.org/10.1061/(ASCE)10523928(1999)125:1(12)

[21] A. Cuoco, E.P. Goldenberg and J. Mark, "Habits of mind: an organizing principle for mathematics curricula," J. of Math. Behaviour, no.15, pp. 375-402, 1996. http://dx.doi.org/10.1016/ s0732-3123(96)90023-1

[22] M. Çalik, and R. Coll, "Investigating socioscientific issues via scientific habits of mind: development and validation of the scientific habits of mind survey," Int. J. of Sci. Educ., vol. 34, pp. 1909-1930, 2012. http://dx.doi.org/10.1080/09500693.2012.685 197

[23] C. Leager, "Fostering scientific habits of mind," Iowa Sci. Teachers J., vol. 32, pp. 8-12, 2005.

[24] E. Orhun and D. Orhun, "Creativity and engineering education," presented at the 41st SEFI Conference, Leuven, Belgium, 2013.

[25] A.M. Connor, S. Karmokar and C. Whittington, "From STEM to STEAM: strategies for enhancing engineering \& technology education,” Int. J. of Eng. Pedagogy, vol. 5, pp.37-47, 2015. http://dx.doi.org/10.3991/ijep.v5i2.4458

[26] A. Craft, "Little c Creativity," in Creativity in Education, A. Craft, B. Jeffrey and M. Leibling, Eds. London: Continuum, 2001, pp. 45-61.

[27] I. MacLeod, "The education of innovative engineers," Eng., Construction and Architectural Manage., vol. 17, pp. 21-34, 2010. http://dx.doi.org/10.1108/09699981011011294

[28] Royal Academy of Engineering and Engineering Council, The Universe of Engineering - A UK Perspective. London: Royal Academy of Engineering, 2000.

[29] B. Lucas, J. Hanson and G. Claxton, Thinking like an engineer: implications for the education system. London: Royal Academy of Engineering, 2014. Available: http://www.raeng.org.uk/news/ news-releases/2014/may/do-you-think-like-an-engineer

[30] S. Fernandez, (2014, November 26). The looming skills deficit, CaSE. [Online]. Available: http://sciencecampaign.org.uk/ ? $\mathrm{p}=15388$

[31] B. Lucas, E. Spencer and G. Claxton, How to teach vocational education: a theory of vocational pedagogy. London: City \& Guilds, 2012. 


\section{PAPER}

\section{Thinking Like An Engineer: Using EngineERING Habits of Mind And Signature PedagO...}

[32] R. Gurung, N. Chick, and A. Haynie, Eds., Exploring Signature Pedagogies: Approaches to Teaching Disciplinary Habits of Mind. Sterling, VA.: Stylus, 2009.

[33] N. Chick, A. Haynie and R. Gurung, Eds., Exploring More Signature Pedagogies: Approaches to Teaching Disciplinary Habits of Mind. Sterling, VA.: Stylus, 2012.

[34] S. Donnison, and M. Marshman, "Professional identity formation: Curriculum considerations for inducting undergraduate students into discursive communities", Int. J. of Pedagogies and Learning, vol. 8, pp. 58-65, 2013. http://dx.doi.org/10.5172/ijpl.2013.8.2.58

[35] L. S. Shulman, "The Signature Pedagogies of the Professions of Law, Medicine, Engineering, and the Clergy: Potential Lessons for the Education of Teachers," presented at Math Science Partnerships (MSP) Workshop: Teacher Education for Effective Teaching and Learning, hosted by the National Research Council's Center for Education, Irvine, California, February 6-8. 2005

[36] D. Peel, "Editorial: Signature Pedagogies and the Built Environment," J. for Educ. in the Built Environment, vol. 6, pp. 1-7, 2011.

[37] L. S. Shulman, "Signature pedagogies," Liberal Educ., Spring, pp. 18-25, 2005.

[38] P. Crowther, "Understanding the signature pedagogy of the design studio and the opportunities for its technological enhancement," J. of Learning Design, vol. 6 pp. 18-28, 2013. http://dx.doi.org/10.5204/jld.v6i3.155

[39] K. J. Crippen and L. Archambault, "Scaffolded inquiry-based instruction with technology: a signature pedagogy for STEM education," Computers in the Schools: Interdisciplinary J. of Practice, Theory, and Applied Research, vol.29, pp. 157-173, 2013. http://dx.doi.org/10.1080/07380569.2012.658733

[40] D. Passey, "Educational technologies and mathematics: signature pedagogies and learner impacts," Computers in the Schools: Interdisciplinary J. of Practice, Theory, and Applied Research, vol. 29, pp. 6-39. 2012. http://dx.doi.org/10.1080/07380569.2012.651092

[41] MY NASA DATA Engineering Design. [Online]. Available: http://mynasadata.larc.nasa.gov/engineering-design/

[42] A. L. Gerhart and R.W. Fletcher, "Project-based learning and design experiences in introduction to engineering courses: Assessing an incremental introduction of engineering skills," presented at the $118^{\text {th }}$ annual conference of the American Society for Engineering Education, Vancouver, B.C. Canada, 2011. Available: http://www.asee.org/public/conferences/1/papers/1570/view

[43] E. F. Crawley, J. Malmqvist, S. Ostlund, D. R. Brodeur and K. Edström, Rethinking Engineering Education: the CDIO approach, $2^{\text {nd }}$ ed. Switzerland: Springer International Publishing, 2014. http://dx.doi.org/10.1007/978-3-319-05561-9

[44] K. Edström and A. Kolmos, "PBL and CDIO: complementary models for engineering education development," European J. of Eng. Educ., vol. 39, pp. 539-555, 2014. http://dx.doi.org/10.1080/ 03043797.2014 .895703

[45] M. Al-Atabi, Think Like An Engineer: Use Systematic Thinking to Solve Everyday Challenges \& Unlock the Inherent Values in Them, Selangor, Malaysia: School of Engineering, Taylor's University, 2014. (Licensed under Creative Commons)

[46] E. de Graaff and A. Kolmos, "Characteristics of problem-based learning,” Int. J. of Eng. Educ., vol. 19, pp. 657-662, 2003.

[47] L. K. Berland, "Designing for STEM integration," J. of PreCollege Eng. Educ. Research, vol. 3, pp. 22-31, 2013. http://docs.lib.purdue.edu/jpeer
[48] L. D. English and D. T. King, "STEM learning through engineering design: Fourth-grade students' investigations in aerospace," Int. J. of STEM Educ., vol.2, pp18, 2015. http://www.stemeducationjournal.com/content/pdf/s40594-0150027-7.pdf

[49] Royal Academy of Engineering, Enhancing Engineering Higher Education: Outputs of the National HE STEM Programme. London: Royal Academy of Engineering, 2012.

[50] STEMNET, STEM Ambassadors, 2015. Available: http://www.stemnet.org.uk/ambassadors/

[51] P. Thomson, C. Jones, K. Jones, and J. Sefton-Hall, The Signature Pedagogies Project: Final Report. Newcastle-Upon-Tyne: Creativity, Culture and Education, 2011.

[52] D. C. Berliner, "Educational psychology as a policy science: Thoughts on the distinction between a discipline and a profession," Canadian J. of Educ. Admin. and Policy, Issue 26, April 15, 2003. http://www.umanitoba.ca/publications/cjeap/articles/miscel laneousArticles/berliner.html

[53] J. Trevelyan, The Making Of An Expert Engineer, Leiden, The Netherlands: CRC Press, 2014. http://dx.doi.org/10.1201/b17434

[54] L. L. Bucciarelli and D. E. Drew, "Liberal studies in engineering a design plan," Eng. Studies, vol. 7, pp. 103-122, 2015. http://dx.doi.org/10.1080/19378629.2015.1077253

[55] R. A. Cheville, "Hidden constraints in the design of liberal studies in engineering," Eng. Studies, vol. 7, pp.147-149, 2015. http://dx.doi.org/10.1080/19378629.2015.1062487

[56] A. E.C. McCants, "The liberal studies curriculum as the basis for an engineering education," Eng. Studies, vol. 7, pp. 145-146, 2015. http://dx.doi.org/10.1080/19378629.2015.1105411

[57] D. Nieusma, "Conducting the instrumentalists: a framework for engineering liberal education," Eng. Studies, vol. 7, pp.159-163, 2015. http://dx.doi.org/10.1080/19378629.2015.1085060

[58] T. Loveland and D. Dunn, "Teaching engineering habits of mind in technology education," Technology and Eng. Teacher, vol. 73, pp. 13-19, 2014

\section{AUTHORS}

Bill Lucas is Director of the Centre for Real-World Learning and Professor of Learning at the University of Winchester, Winchester, United Kingdom. A learning strategy adviser to bodies such as the UK's Health Foundation and Australia's Mitchell Institute, Bill is also the co-creator of a large community of teacher researchers - the Expansive Education Network (e-mail: bill.1ucas@winchester.ac.uk).

Janet Hanson is a researcher with the Centre for RealWorld Learning at the University of Winchester, Winchester, United Kingdom. (e-mail: janet.hanson@winchester.ac.uk).

Funding for this research was provided by Royal Academy of Engineering. This article draws on the authors' original report [29], published by the Academy in 2014 and is an extended and modified version of a paper presented at the SEFI Annual Conference 2014, held 15-19 September, University of Birmingham, Birmingham, UK. Submitted, 15 December 2015. Published as resubmitted by the authors on 08 February 2016. 